\title{
The Short-term Outcome of Early Oral Feeding as Recovery Protocols on Resectable Gastric Cancer
}

\author{
Affan Adib Sungkar ${ }^{1 *}$, Ida Bagus Budhi Surya Adyana ${ }^{2}$ \\ ${ }^{1}$ Department of Surgery, Faculty of Medicine, University of Sebelas Maret, University of Sebelas Maret Hospital, Surakarta, \\ Central Java, Indonesia; ${ }^{2}$ Department of Surgery, Faculty of Medicine, University of Sebelas Maret, Dr. Moewardi General \\ Hospital, Surakarta, Central Java, Indonesia
}

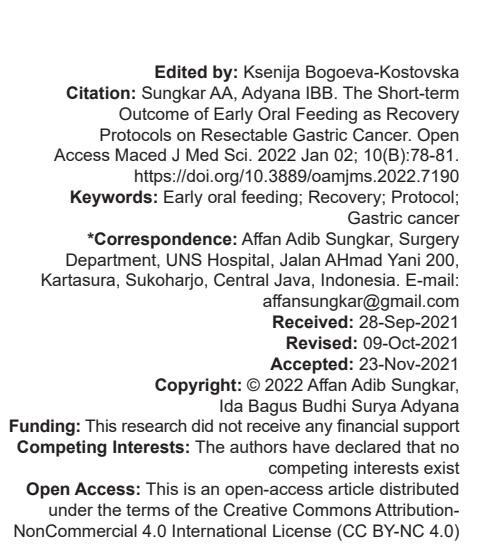

Introduction

Gastric cancer is the fourth most common malignancy globally, showing a prevalence of $8 \%$ and an annual mortality rate of approximately $10 \%$ of all patients diagnosed with gastric cancer. Several authors have proven that surgical resection is the only curative treatment for gastric cancer, ensuring long-term survival. Surgical resection by lymph node dissection is the only treatment that can lead to curation or long-term survival, increasing the 5-year survival rate by up to $45 \%$ [1].

On the other hand, giving early oral feeding after gastric surgery is avoided because, in theory, it caused by secondary mechanical stimulation and increased intraluminal pressure after upper gastrointestinal anastomosis. However, a case-control study from Japan found early oral feeding after gastrectomy to be feasible and showed no evidence of increased morbidity and reduced hospital stay duration [2].

Here, we would like to add to Indonesia's data repertoire on short-term outcomes in resectable gastric cancer patients with early oral feeding: A single study center evaluation. This study aimed to provide short-term outcomes in resectable gastric cancer patients by early oral feeding.

\section{Methods}

\section{Study design}

This research applied a retrospective descriptive study with a cross-sectional approach. The research samples were patients who diagnosed resectable gastric cancer and underwent tumor resection then followed with early oral feeding at RSUD Dr. Moewardi Surakarta in January 2018-August 2019. Gastric cancer patients who also suffered from other types of tumors were excluded from the study. The protocol of early oral feeding was clear fluid diet on the $1^{\text {st }}$ day, dairy milk on the $2^{\text {nd }}$ day, soft chewable diet on the $3^{\text {rd }}$ day, normal daily food on $4^{\text {th }}$ day, and so on. In this study, the variables were age, gender, tumor location, type of resection, and reconstruction.

\section{Sampling technique}

The data were taken from the medical records of gastric cancer patients after tumor resection treated at RSUD Dr. Moewardi Surakarta from January 2018 to December 2019. The data were included age, gender, tumor location, resection, reconstruction, and short-term outcome (anastomotic leak and surgical site infection). 


\section{Data analysis}

The research data obtained were processed utilizing SPSS version 20.0 to calculate the mean age, gender, tumor location, resection, and reconstruction.

\section{Results}

This research was conducted by taking data from gastric cancer patients treated and performed tumor resection at RSUD Dr. Moewardi Surakarta in January 2018-August 2019. The number of samples that met the inclusion criteria was seven samples.

The gastric cancer patients' characteristics in this study were divided into five categories: Age, gender, tumor location, resection, and reconstruction. The results are as follows in Table 1.

Table 1: Distribution of characteristics of gastric cancer patients after tumor resection in RSUD Dr. Moewardi in January 2019-December 2019

\begin{tabular}{|c|c|c|}
\hline Variables & $\mathrm{n}(7)$ & $\mathrm{N}$ \\
\hline Age & $60.14+1.29^{\text {th }}$ & \\
\hline \multicolumn{3}{|l|}{ Gender } \\
\hline Male & 3 & $42.86 \%$ \\
\hline Female & 4 & $57.14 \%$ \\
\hline \multicolumn{3}{|l|}{ Location } \\
\hline Fundus & 1 & $14.28 \%$ \\
\hline Corpus & 3 & $42.86 \%$ \\
\hline Antrum & 3 & $42.86 \%$ \\
\hline \multicolumn{3}{|l|}{ Reconstruction technique } \\
\hline Billroth I & 2 & $28.57 \%$ \\
\hline Billroth II & 4 & $57.14 \%$ \\
\hline Roux-en-Y & 1 & $14.28 \%$ \\
\hline \multicolumn{3}{|l|}{ Resection type } \\
\hline Partial Gastrectomy & 5 & $71.43 \%$ \\
\hline Total Gastrectomy & 1 & $14.28 \%$ \\
\hline Antrectomy & 1 & $14.28 \%$ \\
\hline
\end{tabular}

According to age, from seven samples of gastric cancer patients, six patients were more than 50 years old, with the mean proportion of patients' age being $60.14+1.29$ years. It indicated that the most gastric cancer patients ranged in age over 50 years.

Of the seven samples of gastric cancer patients, three $(42.86 \%)$ were male and four $(57.14 \%)$ were female. The description of the distribution of patients by gender group is shown in Figure 1 .

From the medical record data obtained regarding the tumor location, three people

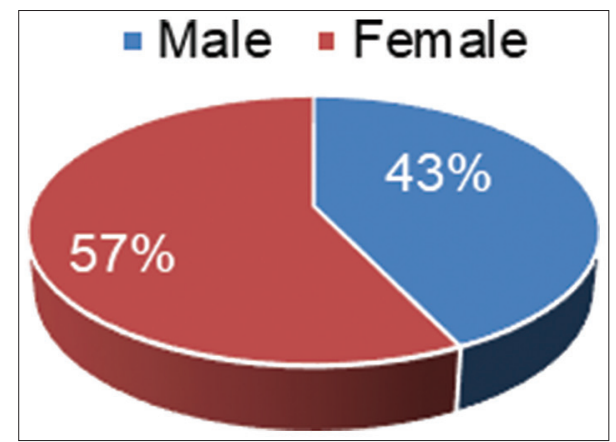

Figure 1: Distribution of patients by gender group
$(42.86 \%)$ were at the corpus location, three people $(42.86 \%)$ were at the antrum location, and one person $(14.28 \%)$ was at the fundus location (Figure 2).

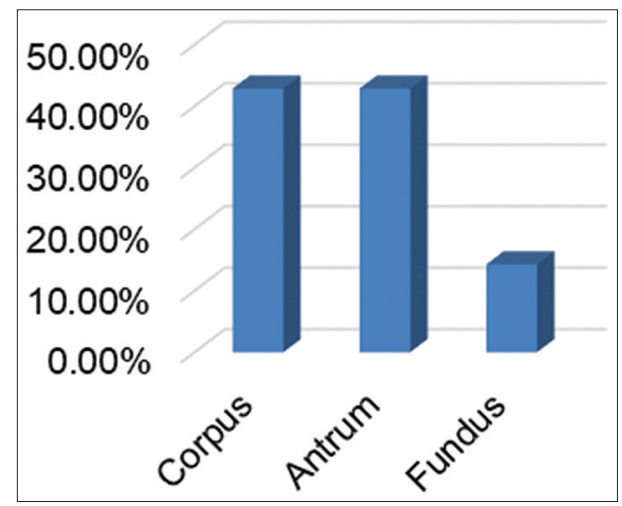

Figure 2: Distribution of patients by tumor location

Based on the data on the types of tumor resection performed on patients with gastric cancer, five $(71.43 \%)$ had partial gastrectomy, one person $(14.28 \%)$ had a total gastrectomy, and one person $(14.28 \%)$ had an antrectomy resection. From these data, the most tumor resection was partial resection. An overview of the patient distribution based on the type of resection performed is displayed in Figure 3.

According to the type of post-resection reconstruction, from seven samples of gastric cancer patients, one person (14.28\%) had Roux-en-Y esophagojejunostomy anastomoses, two (28.57\%) had a Billroth I procedure, and four people $(57.15 \%)$ performed the Billroth II act, displayed in Figure 4.

The short-term outcome in all patients who received early oral feeding on the $1^{\text {st }}$ post-treatment day showed no anastomotic leak and surgical site infection. Description of the short-term data is depicted in following table.

From Table 2, it was found that there was no short-term outcome complication after early oral feeding performed.

\section{Discussion}

Of the total number of patients in RSUD Dr. Moewardi Surakarta between January 2018 and August 2019, seven patients were diagnosed with gastric cancer who had tumor resection and were included in the inclusion category. The limitation patients due to many of them were diagnosed as non-resectable gastric cancer. However, this descriptive research provides in depth view of early oral feeding as a new recovery treatment to resectable gastric cancer patients.

The mean age of patients with gastric cancer in this study was $60.1429+1.28767$ years. However, 
Table 2: The description result of short-term outcome after performed early oral feeding and (anastomotic leak and SSI)

\begin{tabular}{lll}
\hline Outcome & POD 1 $(n=2)$ & POD 2 $(n=5)$ \\
\hline Short-term outcome & $0(0 \%)$ & $0(0 \%)$ \\
Incisional SSI $(n)$ & $0(0 \%)$ & $0(0 \%)$ \\
Anastomotic leak $(n)$ & &
\end{tabular}

another research showed that gastric cancer incidence in the United States mainly occurred in people aged 65-74 [3].

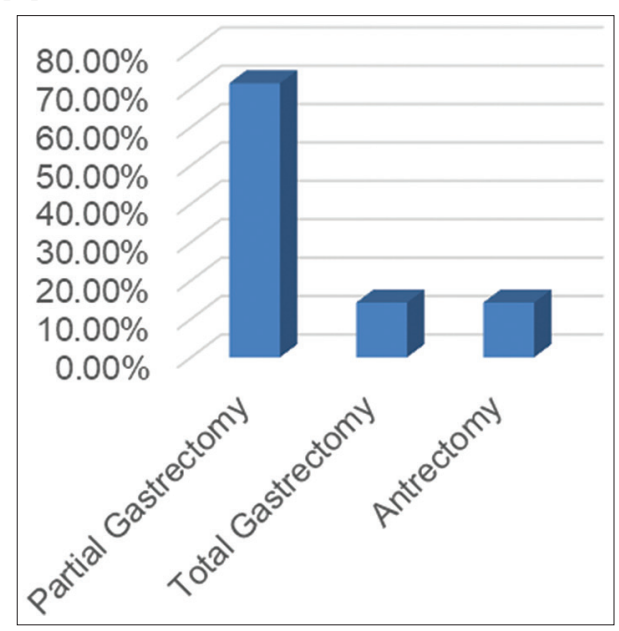

Figure 3: Distribution of patients by type of resection

Based on the data on the distribution of patients according to gender, it was found that four people $(57.14 \%)$ were women. This data contradict the incidence data with the survey results conducted by Knight and Allum in 2019, where the risk of gastric cancer tended to be in men with a ratio of $2: 1$. Meanwhile, in this study, the opposite was found due to the small sample size [4], [5].

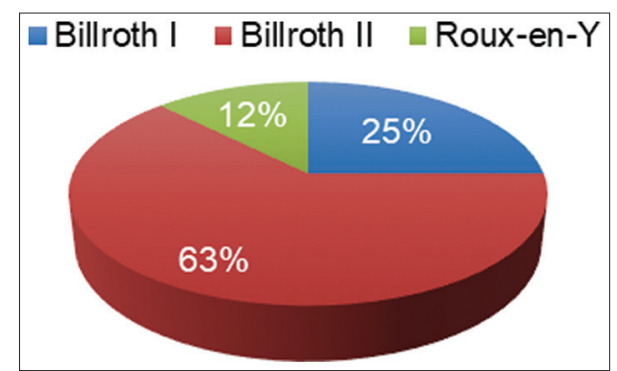

Figure 4: Distribution of patients based on post-resection reconstruction performed

A total of three patients $(42.86 \%)$ were diagnosed with tumor location on the antrum and corpus. These research data results are different from the research conducted by Knight and Allum in 2019, where their study stated that the most common locations for gastric cancer were in non-cardiac cases in developing countries. Based on the cancer location, three patients $(42.86 \%)$ were in the corpus and antrum. The main risk factor for Helicobacter pylori infection resulting in chronic gastritis has a major predilection site in the antrum and corpus area. It is consistent with research and predilection sites for gastric cancer [5], [6].

From the study data, the most commonly performed tumor resection and reconstruction were partial gastrectomy, followed by Billroth II in five patients $(71.43 \%)$ and four patients $(57.15 \%)$, respectively. Resection depends on the location and is followed by reconstruction in the form of partial gastrectomy followed by gastrojejunostomy [7], [8].

The results showed that all patients were given early oral feeding on the $1^{\text {st }}$ post-operative day. The patients were well tolerated by early oral feeding without an anastomotic leak observed during the follow-up period. Furthermore, no surgical site infection was found in this study, and no readmission was associated with post-operative morbidity. It indicated that there was no effect of early oral feeding on short-term outcomes. The results revealed that early oral feeding led to shorter hospital stays and faster restoration of bowel function. Besides, early oral feeding does not appear to increase the risk of surgical site infection complications, anastomotic leak, post-operative mortality, and may be cost-effective compared to conventional care [1], [9], [10].

\section{Conclusion}

There was no correlation between the shortterm outcome in the form of surgical site infection and anastomotic leak in cases of gastric cancer after tumor resection and reconstruction who performed early oral feeding protocols.

This data may not show the true picture of the broader population, so it is necessary to research with a more significant number of samples so that the research results can be more representative in a broader area. The short-term outcome assessment also needs to be expanded to include post-operative disorders (nausea, vomiting, bloating, and diarrhea), hospital stay, treatment costs, post-operative gas start time, and morbidity (fever, pneumonia, and wound bleeding).

\section{References}

1. Tweed T, van Eijden $\mathrm{Y}$, Tegels J, Brenkman $\mathrm{H}$, Ruurda J, van Hillegersberg $R$, et al. Safety and efficacy of early oral feeding for enhanced recovery following gastrectomy for gastric cancer: A systematic review. Surg Oncol. 2019;28:88-95. https://doi. org/10.1016/j.suronc.2018.11.017 PMid:30851919

2. Hur H, Kim SG, Shim JH, Song KY, Kim W, Park CH, et al Effect of early oral feeding after gastric cancer surgery: A result of randomized clinical trial. Surgery. 2011;149(4):561-8. https:// doi.org/10.1016/j.surg.2010.10.003

PMid:21146844

3. Lahmidani N, El Yousf M, Aqodad N, Benajah D, El Abkari M, 
Ibrahimi $\mathrm{A}$, et al. Update on gastric cancer epidemiology and risk factors. J Cancer Res Ther. 2018;9:242-54. https://doi. org/10.4236/jct.2018.93021

4. Hummel R, Bausch D. Anastomotic leakage after upper gastrointestinal surgery: Surgical treatment. Visc Med. 2017;33(3):207-11. https://doi.org/10.1159/000470884

PMid:28785569

5. Knight WR, Allum WH. Gastric tumor. Medicine. 2019;47:309-13.

6. Imai E, Ueda M, Kanao K, Miyaki K, Kubota T, Kitajima M. Surgical site infection surveillance after open gastrectomy and risk factors for surgical site infection. $J$ Infect Chemother. 2005;11(3):141-5. https://doi.org/10.1007/s10156-005-0379-x PMid:15990978

7. Roggin K, Posner MC. Distal subtotal gastrectomy and D1 resection. In: Nussbaum MS, Fischer JE, editors. Master
Techniques in Surgery: Gastric Surgery. Philadelphia, PA: Lippincott Williams and Wilkins; 2019. p. 153-62.

8. Roses SR, Dempsey DT. Schwartz's Principles of Surgery Philadelphia, PA: McGraw-Hill Medical; 2019. p. 1099-166.

9. Lassen K, Kjaeve J, Fetveit T, Tranø G, Sigurdsson HK, Horn A et al. Allowing normal food at will after major upper gastrointestinal surgery does not increase morbidity: A randomized multicenter trial. Ann Surg. 2008;247(5):721-9. https://doi.org/10.1097/ SLA.0b013e31815cca68

PMid:18438106

10. Weimann A, Braga M, Carli F, Higashiguchi T, Hübner M, Klek S et al. ESPEN guideline: Clinical nutrition in surgery. Clin Nutr. 2017;36(3):623-50. https://doi.org/10.1016/j.clnu.2017.02.013 PMid:28385477 